\title{
Economic crisis and the position of employees in Serbia
}

\begin{abstract}
The most vulnerable group in each economic crisis is employees, particularly with regard to their social rights. This does not, of course, mean that other groups are not negatively affected by the crisis - such as, primarily, the unemployed and pensioners. Nevertheless, the position of employees is even more difficult because the current crisis follows on from their already poor position arising from the change of the country's economic system and a bad privatisation model. The challenges concern not only the realisation and protection of social rights - they lead to a reassessment of social models, national employment legislation and social security and protection rights. The crisis has opened many new questions, among them: how much should employees in Serbia fear for their job? Does the existence of the crisis give employers a free hand to violate the rights of employees? And do the state and trade unions have the capacity to protect the rights of employees?
\end{abstract}

Keywords: economic crisis, social rights, abuse of the crisis, position of employees, employers, shadow economy, social security.

\section{Economic crisis and social rights}

The position of employees depends largely on the condition of the economy, both within an economic system and at the global level. The significant economic growth that has been recorded across almost the whole world in the second half of the twentieth and early twenty-first centuries brought, to an unprecedented standard for employees, much more favourable and safer working conditions, union rights and freedoms.

Analysing the process of the establishment and development of social rights, a growing trend may be observed in the sense of the continuous expansion of social rights and improvements in the quality of the position of employees. However, the impact of the economy on employees has its other, not so positive, side. This is primarily reflected in the consequences which every economic crisis leaves behind on all segments of society and for social rights. If there was a doubt about the association between, and the inevitable negative impact of economic crisis on, social rights and concerning the position of employees, then the current global economic crisis has more than clearly confirmed that connection.

That in conditions of economic crisis the question of the status of social rights is always being raised, and the process of the review of the concept of social rights opened, in itself speaks of the cause-related consequential economic crisis and social rights. Each economic crisis is, ultimately, also a crisis of social rights. Considering that each 
economic crisis carries within it a line of political and moral crisis, it is not difficult to conclude that social rights are the first and main target of each economic crisis.

All in all, there is no doubt about the significant correlation between the state of the economy (and economic crises), social rights and the position of employees. Therefore, it can be said that social rights and the position of employees are a very reliable indicator of the state of the economy within a society.

\section{Economic crisis and Serbia}

There were some predictions that the global economic crisis would 'bypass' Serbia, but that did not happen. The economic crisis that has struck a large part of humanity, inevitably left (and is still leaving) its consequences on the economy of Serbia. Its negative effects are evident in every segment of social life. The capital market was targeted first, but the chain crisis spread like a virus to all sectors of the economy. All of this was inevitably reflected on the position of workers in our country, but also on the escalation of workers' protests (in often very radical forms), the intensification of relations between employers and employees, increasing unemployment and the fear of job loss.

Of course, the economic crisis did not affect only employees. Its negative consequences are reflected in the living standards of pensioners and the unemployed, while neither were employers above its reach. Just as anywhere else, companies in Serbia are faced with economic crisis. The most significant effect of the crisis is reflected in companies postponing planned investments because of the fall in sales. A reduced amount of money available, along with an increase in prices and the lower purchasing power which occurs as a result of reduced employment, insolvency and the restrictive policies as regards large companies and the public sector, is inevitably reflected in sales. The population is, in a situation of crisis, mainly focused on purchasing basic resources.

The result of all this is that the number of job vacancies is reduced which can only partly compensate for the dismissals. A closed circle of economic crisis is created. Not wanting to ignore the enormous consequences that the crisis leaves on employers, the inevitable conclusion is that employees are the biggest victims. Due to the lack of possibilities for finding new employment, the fear of job loss becomes greater. Even those whose jobs are not in so much danger are, due to the fall in purchasing power, barely able to provide a basic livelihood for their families. Meanwhile, the fall in company profits is leading to a reduction in investment in protective measures at work, as well as in equipment and the specialisation and training of employees.

One of the negative side-effects of economic crisis is also a decline in the confidence of citizens in the government's ability successfully to overcome the consequences of economic crisis, and a loss of hope in a better tomorrow. Following the global economic crisis taking its own course, the increase in fear among the citizens of Serbia of recession is visible; pessimism has become a usual way of looking at the reality around them. According to research by the Strategic Marketing agency, more than $60 \%$ of Serbian citizens are anticipating a dramatic decline in living standards, while a similar percentage of employees express a fear of job loss. It is evident that this fear sees its biggest increase amongst employees in public administration which, for many years, was considered to be a safe job: in Serbia, there is still a widespread belief that the state is the 
best employer. On the state payroll are 260000 people and, encompassing also those from whom the state orders, half a million.

Chart 1 - Do you think that the world economic crisis will affect a decline in the living standards of citizens in Serbia?

$\square$ Yes, to a large extent $\square$ Yes, but not much $\square$ No $\square$ Don't know
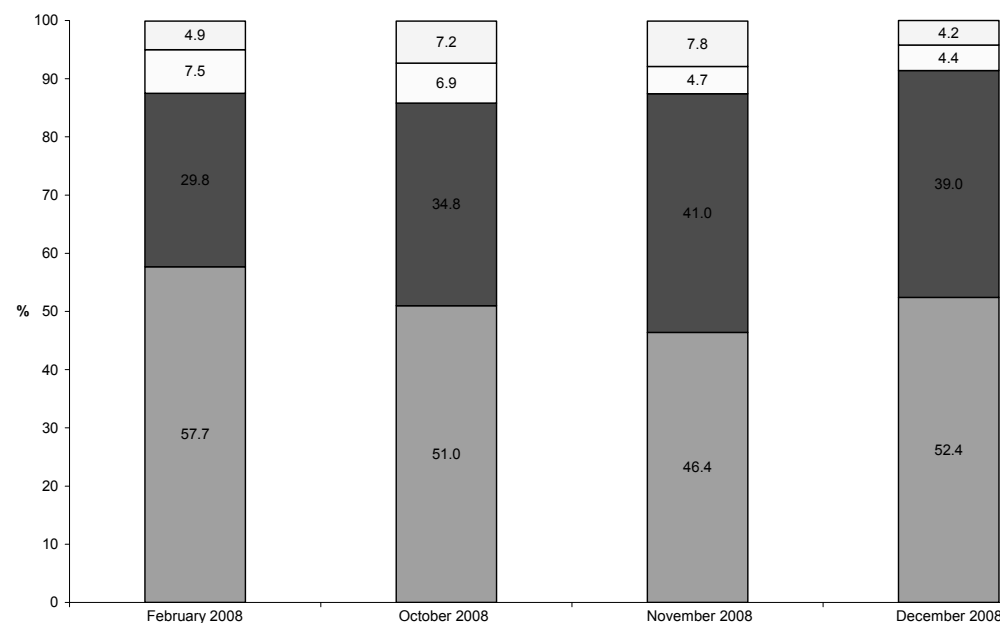

Chart 2 - What are the most important problems currently facing Serbia and those that most concern you personally?

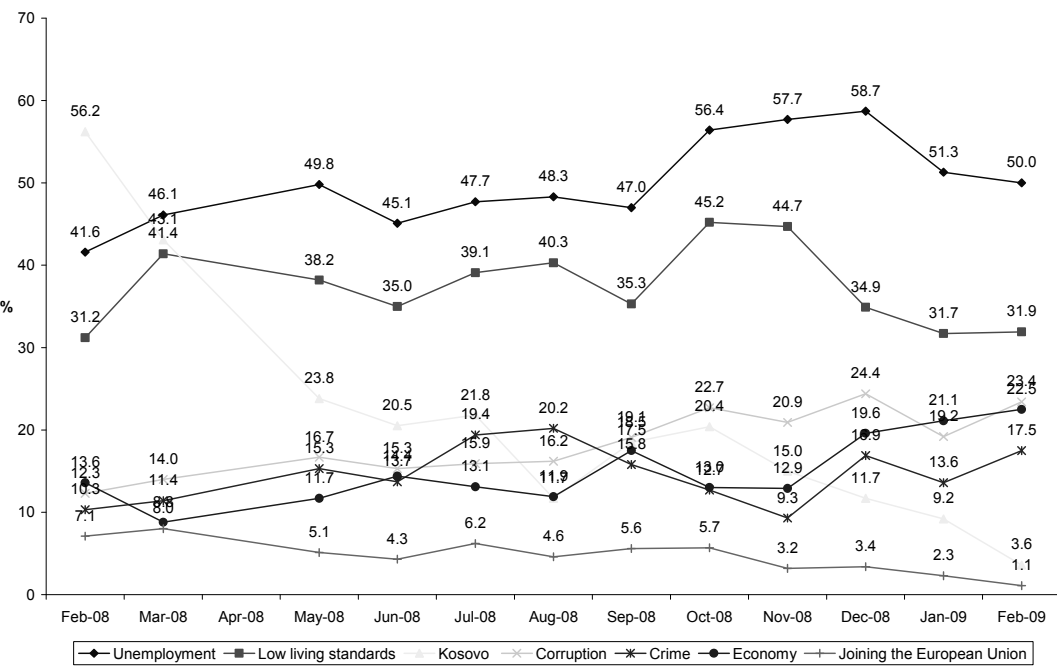

Both charts drawn from research by Strategic Marketing agency. 
This increased pessimism is equally distinctive, both for employees and for the unemployed. The restraint of employers as regards new employment openings is also evident: in even the best case, employers are trying to maintain production despite the declining number of existing employees. We know that new employment in public administration is prohibited, but it is evident that the finding of employment for the unemployed is very difficult.

The private sector employs about 1.2 million people. Their fate is largely dependent on the liquidity of these companies. The increased levels of insolvency amongst companies in the private sector may well lead to potentially massive lay-offs. Around 900000 people are employed in small- and medium-sized companies that are most exposed to the negative effects of the global economic crisis. Otherwise, these companies take up more than $50 \%$ of the budget of Serbia.

Unemployment in Serbia has, according to the National Employment Service in the period from October 2008 up to April 2009, increased from $14 \%$ to $15.6 \%$.

Employers share their pessimism equally with employees and the unemployed. For them, this is reflected primarily in a fear for the future of the company due to the reduced volume of business but also due to the additional burdens that the state could introduce because of the lack of budgetary resources. In the second quarter of this year, GDP was practically 4 per cent lower than in the same period of 2008. The largest decrease was in manufacturing industry (20\%), as well as in construction and catering.

During 2009, the trend towards a decrease in exports as well as in imports has been continued; the main factor behind this is, in any case, the global economic crisis that has led to a fall in economic activity in the world as well as in Serbia. The fall in exports has been largely conditioned also by the significantly reduced prices of primary products on world markets; exports of primary products assume a major share of the export structure of Serbia. The main cause of the reduction in imports is the fall in industrial production and consumption in Serbia.

\section{Abuse of the economic crisis}

Every economic 'disaster' which hits a society highlights all the problems and inconsistencies that exist within that society, in addition to the negative effects that have been manifested in all the other societies which have also been affected by it. In the same way, this economic crisis in Serbia has shown, as under a magnifying glass, an insufficient privatisation process, a lack of social dialogue, the under-development of trade unions in defending workers' rights and issues in public administration, amongst others. However, besides this usual, and more or less inevitable, set of consequences that every economic crisis carries along with it, we can also consider those who seek to abuse it, mostly employers but not so rarely workers, too.

In the guise of the major world economic crisis, employers often seek to find a justification for their poor business results which, sometimes, have nothing to do with that crisis. And that usually takes effect on the back of employees. The excuse for all this is a surplus number of employees and, of course, release programmes. Cases of the violation of employment contracts, illegality and various types of arrogant behaviour are multiplying (for example, the failing of workers; illegal dismissals, frequently 
without any explanation; and overtime being longer than allowed, and often unpaid). When giving employees release, some employers do not respect even the minimum legal obligation to put a decision on release in writing, cancelling the contract verbally in such a way that they say only to the employee that he or she does not have to come to work the next day.

The state as an employer is also dealing with the consequences of the state's politicised apparatus by reducing the number of employees. The problem in all this is that, generally, the most capable and the most trained are the ones who are leaving, since they are able to find new employment more quickly, and the effects of the reduction of employees in the state apparatus are negligible in the short period when they are most needed.

Employees, individually or through their trade unions, are also using the economic crisis as an alibi for a lack of will and of the ability to adapt to new business conditions, or to the introduction of labour discipline and accountability for their work. Frequently behind workers' seemingly legitimate demands lies a desire for the annulment or prevention of privatisation and a return underneath the wing of the state and the old ways. It is rarely done directly, but is usually hidden behind a concern for the position of employees, alleged social dialogue, negotiation and reconciliation efforts, but with little real desire to come to a resolution of the dispute.

A poll on the position of employees in Serbia was conducted online at www.poslovi.infostud.com. Approximately $52 \%$ of participants in the survey saw the main reason for shared failure precisely in the abuse of the economic crisis by employers, while $17 \%$ considered that the insufficient productivity of workers was to blame for their 'responsible' dismissal. Only $10 \%$ of participants considered that the economic crisis was the actual cause of the increased numbers of discharges. These results should certainly be taken with a serious amount of reservation, since the participants were in a much greater number employees than employers.

However, the other results of this survey need to be interpreted far more seriously, since they describe the position of employees in Serbia at the time of the global economic crisis. Almost $12 \%$ of respondents confirmed that they have no holidays at all while just under one-half (45\%) said they have a leave entitlement which is less than regular. Over $60 \%$ of respondents have problems taking a day off.

In the worst position are employees working in the shadow economy. Besides not having many of the rights of those who are legally employed, people in this situation are considered to encompass the most at-risk group as regards workplace injuries. Approximately $32 \%$ of those fatally injured due to injuries at work are shadow economy workers. People who are engaged by employers without work contracts are in the most seasonal of work areas. They work without any, or with insufficient, introduction to the technologies with which they are working. Very often, they are not professionally qualified for the tasks that they are performing. In addition, employers rarely provide them with adequate workplace protective equipment. Owing to these reasons, this category of workers is at an increased risk of injury.

During a time of crisis, employers engage workers in the shadow economy more than they do usually, most often for jobs as waiters and retail workers, as well as construction and textile workers. It is estimated that about half a million workers are en- 
gaged in the shadow economy in Serbia. The Work Inspectorate has shown that illegal operations are usually focused on employment without a work contract, including also work without the payment of social contributions; the payment of wages below the established minimum; the payment of wages 'in hand'; and the non-payment of overtime.

Most exposed to work in the shadow economy are young, unskilled workers and refugees and displaced people. The main reasons for this kind of engagement are workers' alleged inability to find lawful employment and the low wages from regular employment, as well as the high taxes and contributions alleged by employers. Besides the insufficient legal provisions which are hampering the work of the Inspectorate, which is primarily concerned with the absence of employers' obligations to record contracts of employment and to the deadlines for the registration of employees, the response to the increased level of shadow economy labour has been little more than low-level fines which are more symbolic as regards determined offenders of the law and which are often below the regular minima, even for employers for which the most recent occasion was not the first time that they have violated the legal provisions of the Labour Law.

\section{Measures of protection against the economic crisis}

It is impossible to prevent all the negative consequences of the global economic crisis but, in any case, something can be done to reduce its effects. The most important role in this process should be, and is, held by the government of the Republic of Serbia. The involvement of the government should primarily be directed towards the social aspect; in other words, to regulate the obligations of employers to employees in the area of the regular payment of salaries, as well as in the domain of the payment of pensions and health insurance contributions - both of which need anyway to be done on a regular basis. This problem is particularly pronounced in a number of privatised companies.

Considering the problems that have worsened the social position of employees in Serbia as a result of the economic crisis and its abuse, the government has adopted the 'Social Security Plan', which provides for the resolution of, at most, a few of the problems that are facing employees in Serbia. Essentially, the Plan troubleshoots in the following areas:

- payment of contributions for pensions and disability insurance

- payment of contributions for the health insurance of employees for whom such a right is not provided by the employer

- payment of one-off assistance for the most vulnerable employees

- deferred payment of electricity bills for the most vulnerable employees

- retraining of employees.

\section{Payment of contributions for pensions and disability insurance}

One of the major problems facing employees is service connectivity in cases where the employer has not regularly paid contributions for pensions insurance. According to the IRS, RFPIO and the Work Inspectorate, contributions for pensions and disability insurance were not paid in respect of a large number of employees in the period between 
2005 and 2009; consequently, these people do not have the ability to realise the rights associated with pensions (the right to a pension and to carer's allowance, etc.).

Considering the importance of this issue to employees, the government is going to provide the necessary funds which will allow RFPIO to make a link with the service records of all employees in state companies and privatised entities, where this problem is at its most acute. The issue at stake here is the obligations of the employer, so the Republic of Serbia intends to regulate such an obligation by becoming a creditor of the company and settling claims on the basis of one of the following options, or a combination of them both:

1. re-schedule the claims on the basis of interests and establishing securities over the property of the owner of the company which is not owned by the subject of privatisation

2. convert debts into capital in the companies.

Payment of contributions for health insurance to employees for whom this right is not provided by the employer

With contributions for compulsory health insurance not being paid in respect of a large number of employees for 2009, those employees do not have certified health records and can not use the services of the health care system for themselves and their family members in the usual way.

In the short term, the government is to eliminate this problem by paying health insurance for all employees for whom the employer has not paid contributions, which will enable health records to be certified for 2009. Considering that the issue here again is the obligations of the employer, the Republic of Serbia aims to regulate employer obligations by becoming a creditor of the company and settling the claims concerning the payment of contributions for pensions and disability insurance.

In the long-term, the resolution of this issue will be facilitated by changing the regulations and tightening the controls on employers which, in the future, will not be able to pay salaries without paying contributions for health insurance.

\section{Payment of one-off assistance for the most vulnerable employees}

One-off payments to help the most vulnerable workers will be carried out in companies in which the following conditions are cumulatively met:

1. majority state-owned enterprises, or privatised entities

2. no agreement has been reached between employer and employees

3. a suspension of work in accordance with the Labour Law has taken place.

The right to a one-off payment can help assist company employees who have not received wages on three or more occasions, and where:

- the employee is the only household member who is employed, or

- both spouses work in the same company, or

- the employee is a single parent of a small child, or

- the employee has a multi-member family.

One-off assistance is paid in a singular amount of 5000 dinars. It does not represent the payment of employee salaries, or of part or the whole of the duties of the employer 
on that basis; employees affected should continue to claim the entire amount of unpaid wages along with the corresponding interest. In accordance with the above, the payment does not include one-off assistance with regard to the payment of related contributions for pensions and health insurance.

\section{Deferred payment of electricity bills for the most vulnerable employees}

Employees in companies that have not received wages for several months are faced with a series of survival problems, of which one of the most serious threats is exclusion from the electricity network. This problem has occurred despite the measures that the Serbian Electric Power Company (EPS) has taken regarding socially-vulnerable groups to facilitate payment for electricity and which has encompassed about 300000 people.

These measures are based on the government providing, in agreement with the EPS, the most vulnerable employees with one-off support in the form of a rescheduling of outstanding obligations to the EPS, with the prolongation of debt payments, or else the discharge of debt, for employees that:

- have not received salaries for more than three months, and

- have a member of the household earning less than $50 \%$ of the minimum wage.

\section{Retraining of employees}

The problem of unemployment existed in Serbia before the global economic crisis and is linked to the adjustment of the economy to a market economy and to international competition. The occurrence of the economic crisis has further highlighted this issue and has indicated the need for a systematic resolution. It is expected that the trend of a slight increase in unemployment will continue in the future, primarily due to the reduced volume of economic activity and the lack of foreign direct investment.

In this sense, the government intends, through co-operation between the National Employment Service and the Ministry of Education, to prepare an action plan to implement a programme of retraining and training for unemployed people.

Besides these measures contained in the Social Security Plan, measures have also been taken by the government of the Republic of Serbia in order to prevent abuses and economic crime; convert the outstanding obligations owed to the public revenue of the Republic of Serbia and to public enterprises regarding the capital of state enterprises and privatised organisations; conclude agreements on social partnership with the social partners; and provide public meetings in cases of the violation of the rights of employees and the suspension of work. 


\section{References}

Research on the economic crisis Strategic Marketing/Network for political accountability.

Social Security Plan Government of the Republic of Serbia.

Marinkovic, D and V. Marinkovic Social rights conflicts between industrial and social partnership.

Kostic, D and V. J. Peric Optimal conditions for reconciliation in collective work disputes.

Branko Lubarda Social rights and economic crisis. 